\title{
Embedded Systems - Missile Detection/Interception
}

Luis Cintron

University of South Florida

\author{
Advisors: \\ Masahiko Saito, Mathematics and Statistics \\ Mayur Palankar, Computer Science \& Engineering \\ Problem Suggested By: Mayur Palankar
}

Follow this and additional works at: https://digitalcommons.usf.edu/ujmm

Part of the Mathematics Commons

UJMM is an open access journal, free to authors and readers, and relies on your support:

Donate Now

\section{Recommended Citation}

Cintron, Luis (2010) "Embedded Systems - Missile Detection/Interception," Undergraduate Journal of Mathematical Modeling: One + Two: Vol. 2: Iss. 2, Article 2.

DOI: http://dx.doi.org/10.5038/2326-3652.2.2.2

Available at: https://digitalcommons.usf.edu/ujmm/vol2/iss $2 / 2$ 


\title{
Embedded Systems - Missile Detection/Interception
}

\begin{abstract}
Missile defense systems are often related to major military resources aimed at shielding a specific region from incoming attacks. They are intended to detect, track, intercept, and destruct incoming enemy missiles. These systems vary in cost, efficiency, dependability, and technology. In present times, the possession of these types of systems is associated with large capacity military countries. Demonstrated here are the mathematical techniques behind missile systems which calculate trajectories of incoming missiles and potential intercept positions after initial missile detection. This procedure involved the use of vector-valued functions, systems of equations, and knowledge of projectile motion concepts.
\end{abstract}

\section{Keywords}

Projectile Motion, Vector Valued Functions, Embedded System

Creative Commons License

(c) (1) (9)

This work is licensed under a Creative Commons Attribution-Noncommercial-Share Alike 4.0 License. 


\section{TABLE OF CONTENTS}

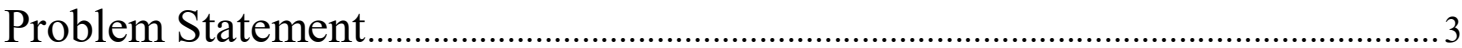

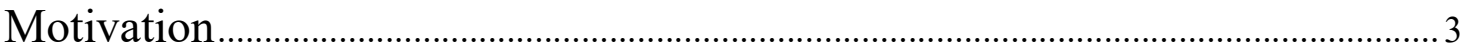

Mathematical Description and Solution Approach ………………………………....

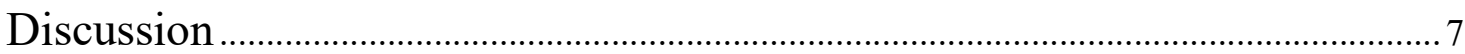

Conclusion and Recommendations........................................................................11

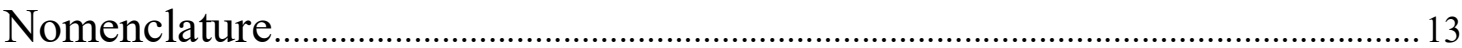

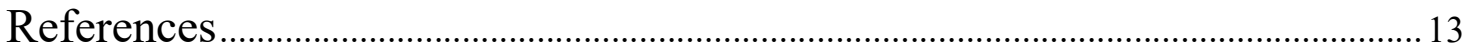

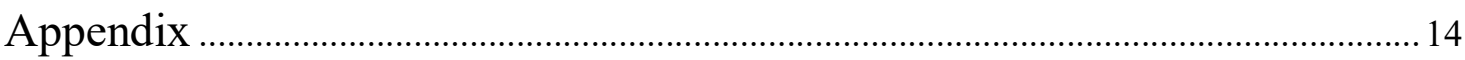




\section{PROBLEM STATEMENT}

Consider a possible scenario where an unmanned border security radar station detects an incoming missile entering the country at a speed of $2,000 \mathrm{~m} / \mathrm{s}$. The missile was detected at the horizon and was seen at an angle of $20^{\circ}$ above the surface. It is estimated that the missile is $50,000 \mathrm{~m}$ above the surface of the earth and headed at an angle of $80^{\circ}$ in relation with the normal. The station has four automatic surface-to-air missiles with the features listed in Table 1. Assume the firepower of each missile is capable of successfully intercepting the incoming missile.

\begin{tabular}{|ccc|}
\hline Missile Type & Speed & Operation Delay \\
\hline Patriot & Mach 5.0 & $72 s$ \\
\hline KS-1 & $750 \mathrm{~m} / \mathrm{s}$ & $30 \mathrm{~s}$ \\
\hline HQ-9 & Mach 4.2 & $70 s$ \\
\hline S-300 & $1,800 \mathrm{~m} / \mathrm{s}$ & $42 \mathrm{~s}$ \\
\hline
\end{tabular}

Table 1: Missile Speeds and Operation Delay

Based on the information above, find which of these missiles are suitable for intercepting the incoming missile and also find the location of the interception and also angle (with respect to ground) of the missile that has to be launched. The missile has to be intercepted at least $5,000 \mathrm{~m}$ above the surface not to cause any damage on the ground.

\section{Motivation}

The usefulness of a mathematical approach when solving real world problems is very significant. It makes a huge difference when adding up all the factors that affect the problem and its outcome. This problem is useful to both science and engineering because it implements 
various topics that involved physics and calculus to predict the behavior of a moving object in space over a period of time. These concepts can be used to demonstrate how a moving object's trajectory, in this case the missile's trajectory, depends on the magnitude and direction of the initial velocity and the acceleration due to the forces acting upon the missile, in scenario, gravity. Air resistance was not taken into consideration when solving this problem.

The projectile motion analysis of the missiles through the use of vector-valued functions included integration of vector-valued functions in two dimensional planes techniques. Furthermore, the intercept position and time was calculated by using systems of equation and trigonometric techniques. As mentioned already these steps were simplified using advanced computing software.

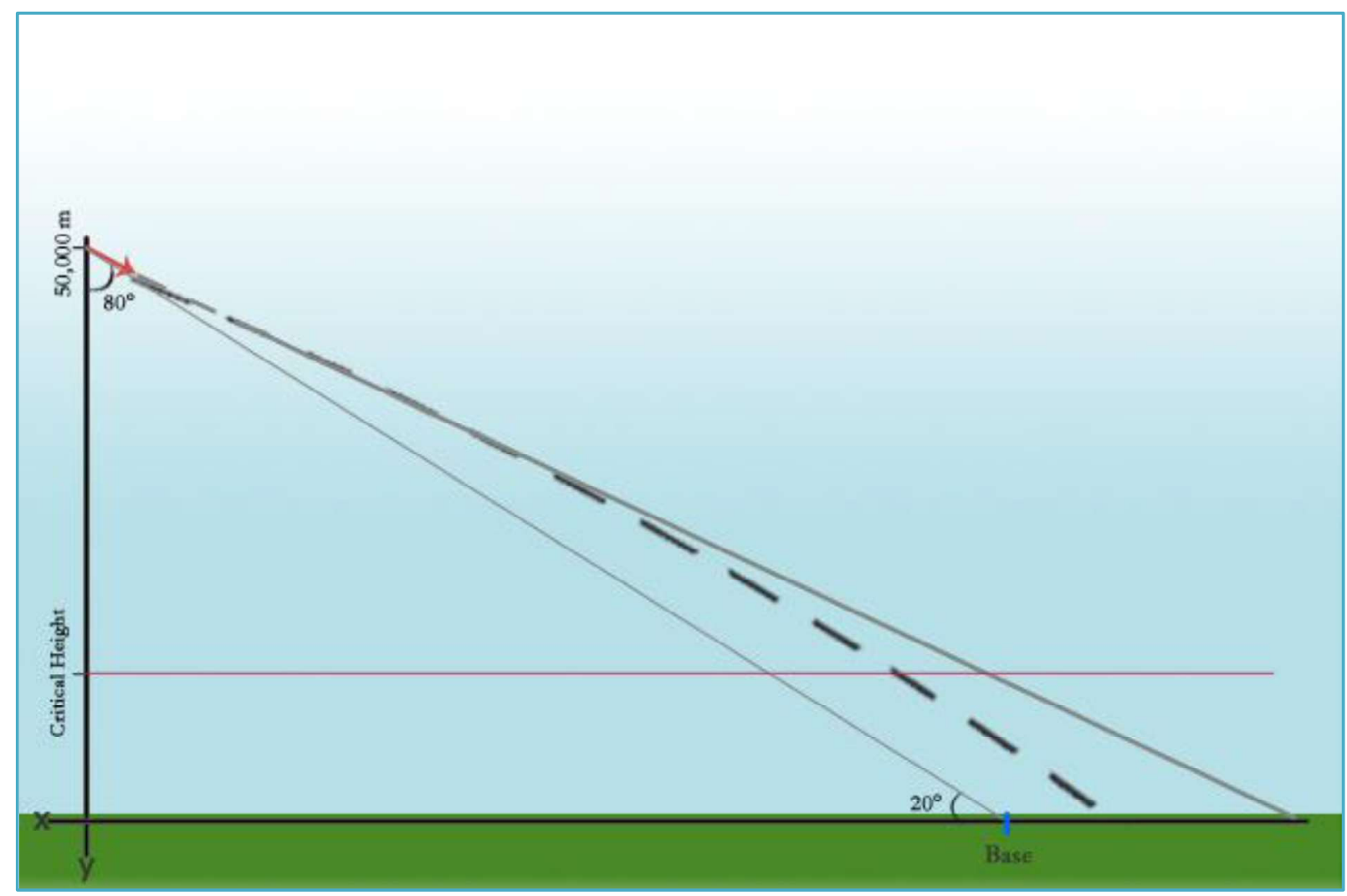

Figure 1: Incoming Missile Location at Detection Time. 
In essence, the objective of this project is to solve the assigned problem involving projectile motion and describe the procedure and solution by using a fundamental mathematical approach that includes the use of calculus concepts.

\section{MATHEMATICAL DESCRIPTION AND SOLUTION APPROACH}

The problem states that the incoming missile was detected at a height of $50,000 \mathrm{~km}$ above the ground with a speed of $2,000 \mathrm{~m} / \mathrm{s}$ headed at an angle of $80^{\circ}$ in relation with the normal and $20^{\circ}$ above the surface. Therefore, the time at which the incoming missile was detected can be label as initial time $t_{0}=0$.

Given this information, it is possible to calculate the location of the missile detection system base and set up vector-valued functions to describe the motion of the incoming and outgoing missiles. The location of the base with respect to the incoming missile at $t_{0}$ is

$$
(x, y)=\left(\frac{50,000}{\tan 20^{\circ}}, 0\right)=\left(50,000 \cot \left(20^{\circ}\right), 0\right) \approx(137,374,0) .
$$

The position of the missiles is described by the vector-valued function

$$
r(t)=x(t) \boldsymbol{i}+y(t) \boldsymbol{j}
$$

Because the only force acting upon the missiles is that of gravity, which has an acceleration $a(t)$ of $9.8 \mathrm{~m} / \mathrm{s}^{2}$ in the $-\boldsymbol{j}$ direction, the velocity over time function is given by

$$
\begin{aligned}
v(t) & =\int a_{x}(t) \boldsymbol{i}+a_{y}(t) \boldsymbol{j} \\
& =\int 0 \boldsymbol{i}-9.8 \boldsymbol{j} \\
& =\left(v_{0}\right) \boldsymbol{i}+\left(v_{0}-9.8 t\right) \boldsymbol{j}
\end{aligned}
$$


Likewise, the position function of missiles is given by the integral of their velocity function

$$
\begin{aligned}
r(t) & =\int v_{x}(t) \boldsymbol{i}+v_{y}(t) \boldsymbol{j} \\
& =\int v_{x} \boldsymbol{i}+\left(v_{y}-9.8\right) \boldsymbol{j} \\
& =\left(x_{0}+v_{x} t\right) \boldsymbol{i}+\left(y_{0}+v_{y} t-\frac{9.8 t^{2}}{2}\right) \boldsymbol{j}
\end{aligned}
$$

The problem states that the incoming missile must be intercepted before reaching a critical height of 5,000 $\mathrm{m}$. Therefore it is important to find the time $t_{\text {critical }}$ it takes for the incoming missile to reach the critical height. This can be done by setting the $\boldsymbol{j}$ component of the position vector equal to the critical height $y_{\text {critical }}$, and solve for $t_{\text {critical }}$ :

$$
y_{\text {critical }}=y_{0}+v_{y} t_{\text {critical }}-\frac{9.8 t_{\text {critical }}{ }^{2}}{2} \text {. }
$$

Once the critical time is found, it can be compared with the time delays of the different missiles that could be used to intercept the incoming missile. Only those with a time delay smaller that the critical time $t_{\text {critical }}$ will be considered by the embedded system as possible interceptors.

In order to find the point(s) of interception and the launch angle for the outgoing missile, a system of equations must be set up. It is more convenient to set the $\boldsymbol{i}$ components equal to each other and solve for $t_{\text {intercept }}$. It is important to keep in mind that the time for the outgoing missiles will be given by $\left(t-t_{\text {delay }}\right)$ where $t_{\text {delay }}$ is the operation delay for the specific missile interceptor. Repeat the same procedure with the $\boldsymbol{j}$ components, plug in $t_{\text {intercept }}$ and solve for the angle $\theta$ of elevation from the ground to launch the outgoing missile. Once $t_{\text {intercept }}$ and $\theta$ 
are found, it is possible to verify that the position at $t_{\text {intercept }}$ of both incoming and outgoing missiles is the same, meaning a successful interception of the incoming missile:

$$
r_{\text {incomming }}\left(t_{\text {intercept }}\right)=r_{\text {outgoing }}\left(t_{\text {intercept }}\right)
$$

\section{DISCUSSION}

With the given information, the location of the base with respect to the incoming missile at $t_{0}$ was calculated in (1). It is known that the missile is traveling at a constant velocity of $2,000 \mathrm{~m} / \mathrm{s}$ at $80^{\circ}$ from the normal in both $\boldsymbol{i}$ and $\boldsymbol{j}$ direction and it was first spotted at a height of $50,000 \mathrm{~m}$. Thus, the position function that describes the motion of this missile is:

$$
r_{\text {incomming }}(t)=\left(2,000 \sin \left(80^{\circ}\right) t\right) \boldsymbol{i}+\left(50,000-2,000 \cos \left(80^{\circ}\right) t-4.9 t^{2}\right) \boldsymbol{j}
$$

The incoming missile must be intercepted before it reaches a height lower than 5,000 $\mathrm{m}$. The time for the missile to reach the critical height of 5,000 $\mathrm{m}$ was found using the function that describes its motion in the $\boldsymbol{j}$ direction as follows:

$$
5,000=50,000-2,000 \cos \left(80^{\circ}\right) t-4.9 t^{2} .
$$

Solving (8) yielded

$$
t_{\text {critical }}=66.74 \mathrm{~s} \text {. }
$$

This means that the Missile Detection System has around 67 seconds to decide which missile to use, aim and fire before the incoming missile reaches the critical height. The system has the option of using any of the four different types of missiles it contains, but due to the time constraint of 66.74 seconds, the Patriot and the HQ-9 missiles are discarded because their time 
delay is higher than the time constraint. The Patriot missile has an operation delay of 72 seconds and the HQ-9 missile has an operation delay of 70 seconds; both of which exceed $t_{\text {critical }}$ (see Table 1). This leaves the system with only two options: the KS-1 missile and the S-300 missile.

The next step in verifying which missile is the best option is to check which one would be able to intercept the incoming missile after their operation delay and before reaching the critical height. This can be done by setting the incoming missile's position equation equal to that of the outgoing missile to find the time of interception and angle of launch.

Note that by (1) and (4) the outgoing missile will satisfy the following:

$$
\begin{aligned}
r_{\text {outgoing }}(t) & =\left(50,000 \cot 20^{\circ}-v \cos (\theta)\left(t-t_{\text {delay }}\right)\right) \boldsymbol{i} \\
& +\left(v \sin \theta\left(t-t_{\text {delay }}\right)-4.9\left(t-t_{\text {delay }}\right)^{2}\right) \boldsymbol{j} .
\end{aligned}
$$

Using the values for the KS-1 missile in Table 1 with (10), we got

$$
\begin{aligned}
r_{K S-1}(t)= & \left(50,000 \cot 20^{\circ}-750 \cos (\theta)(t-30)\right) \boldsymbol{i} \\
& +\left(750 \sin \theta(t-30)-4.9(t-30)^{2}\right) \boldsymbol{j}
\end{aligned}
$$

Equation (6) says to equate (7) and (11). Equating these by their $\boldsymbol{i}$ and $\boldsymbol{j}$ coordinates gave a system of equations for $t_{\text {intercept }}$ and the angle $\theta$ :

$$
\left\{\begin{array}{c}
2,000 \sin \left(80^{\circ}\right) t=50,000 \cot 20^{\circ}-750 \cos (\theta)(t-30) \\
50,000-2,000 \cos \left(80^{\circ}\right) t-4.9 t^{2}=750 \sin \theta(t-30)-4.9(t-30)^{2}
\end{array}\right.
$$

The Appendix contains details for solving (12). For the KS-1 missile

$$
t_{\text {intercept }} \approx 60.9187 \mathrm{~s} \quad \text { and } \quad \theta \approx 41.4^{\circ} \text {. }
$$


At after 60.9187 seconds of the incoming missile being spotted, the KS-1 missile will intercept it at position

$$
(x, y)=(119986,10659) \text {. }
$$

This means that at time $t=0$ the incoming missile is spotted at $(0,50000)$ and the missile base prepares to fire the KS-1 missile to intercept. Thirty seconds later, the KS-1 missile fires at an angle of $41.4^{\circ}$ and intercepts the incoming missile approximately 30.9 seconds later at the position listed above (14). Note that this missile intercepts the incoming missile within 6 seconds of the critical time $t_{\text {critical }}=66.74 \mathrm{~s}$ found in (9). See Figure 2 below.

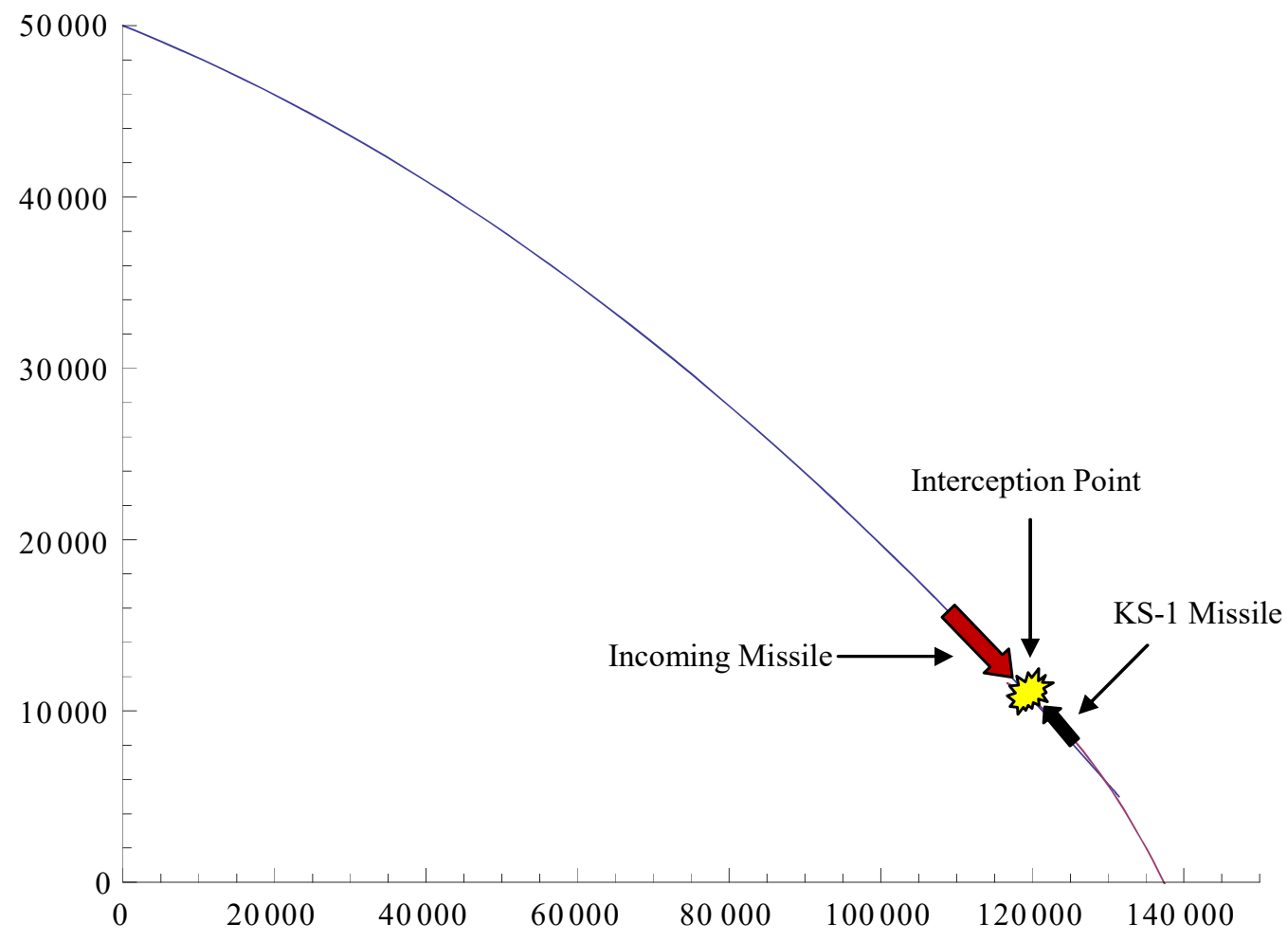

Figure 2: Incoming Missile and KS-1 Intercepting Missile Trajectories Plot 
The same procedure was used to calculate the interception time $t_{\text {intercept }}$ and launch angle $\theta$ for the S-300 missile interceptor. Referring to Table 1, the velocity of the S-300 missile is $1,800 \mathrm{~m} /$ $s$ and the time delay is $42 s$. Similar to (12), our system is

$$
\left\{\begin{array}{c}
2,000 \sin \left(80^{\circ}\right) t=50,000 \cot 20^{\circ}-1,800 \cos (\theta)(t-42) \\
50,000-2,000 \cos \left(80^{\circ}\right) t-4.9 t^{2}=1800 \sin \theta(t-42)-4.9(t-42)^{2}
\end{array}\right.
$$

and resulted in

$$
t_{\text {intercept }} \approx 57.6313 \mathrm{~s} \quad \text { and } \quad \theta \approx 32.0^{\circ} \text {. }
$$

The position of the incoming missile, 57.6 seconds after being detected is

$$
(x, y)=(113511,13710)
$$

Therefore the S-300 missile is also suitable for intercepting.

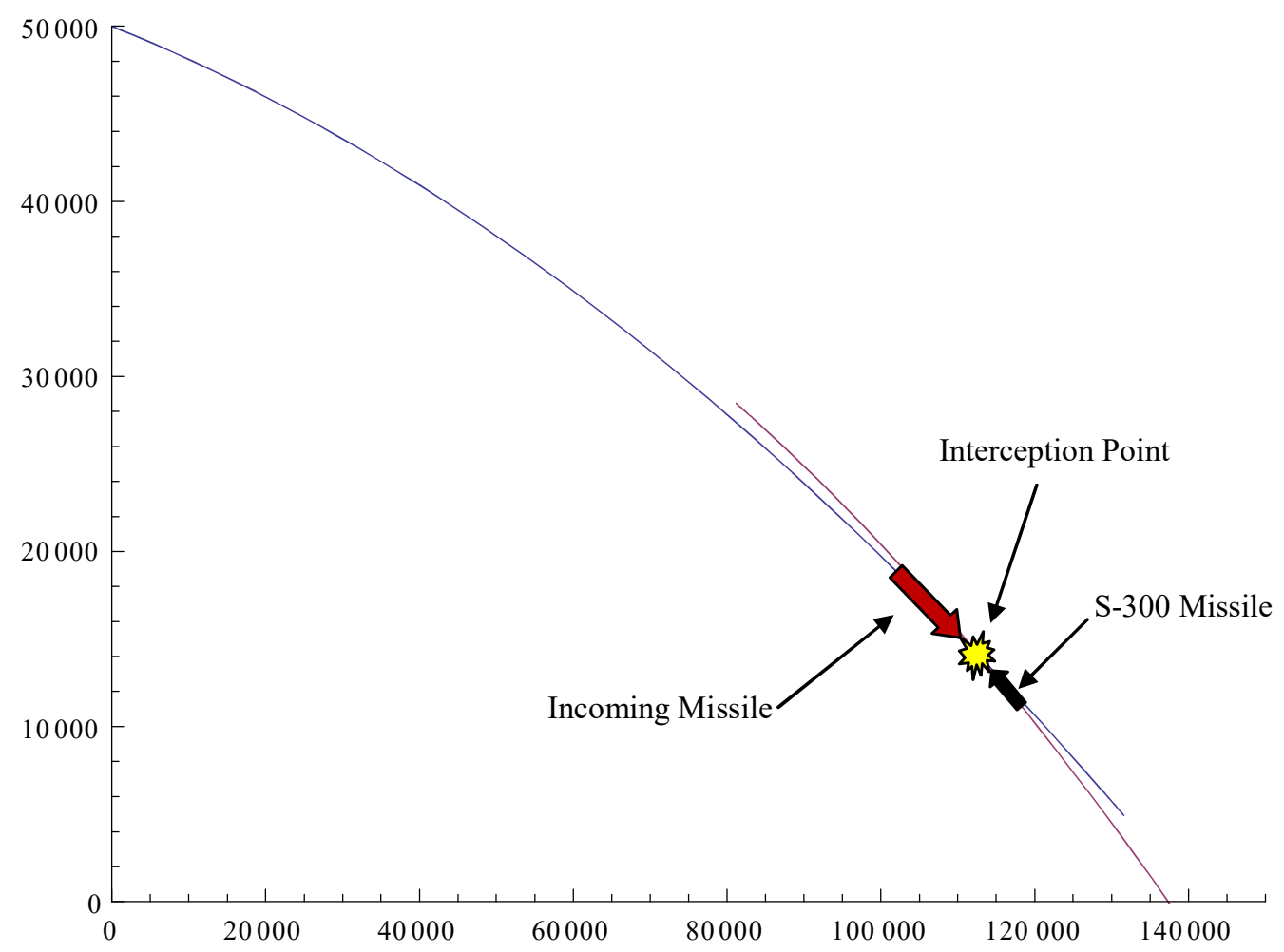

Figure 3: Incoming Missile and KS-1 Intercepting Missile Trajectories Plot 
Consequently, the objective of this project was met by finding both the KS-1 and S-300 to be suitable for intercepting the incoming missile. Understanding of this kind of problem has led to the creation of better types of embedded systems in devices such as missile detection systems which shield many countries. The engineering behind these systems can get very complex because real world factors are added into the calculations and many case scenarios are taken into consideration, but the fundamental concept for calculating trajectories and checking for intercepts will remain the same.

\section{CONCLUSION AND RECOMMENDATIONS}

This work demonstrated the mathematical techniques behind missile detection / interception embedded systems which are used to calculate the trajectory of incoming missiles, the position of interception at a given time after detection and the angle of elevation at launch for the interceptor missile.

The mathematical solution involved the use of vector-valued functions, systems of equations, and knowledge on projectile motion concepts. Mathematica was used as a tool for doing the calculations and plotting the position graphs of the missiles.

With the given information in the problem, it was possible obtain the equations of motion of the missiles involved and find the most convenient missile for intercepting the incoming one. With the incoming missile's motion equation, the time for the missile to reach a critical height was calculated and compared to the operation delay of all missiles in the missile detection / interception system. As a result, two missiles were found not to be able to reach the incoming missile before reaching the critical height; therefore they were discarded from the possibilities. 
For the other two missiles, KS-1 and S-300, the possible time of impact was calculated and then used to find the angle at which the interceptors were to be fired. The KS-1 missile was found to intercept the incoming missile $60.9187 s$ after detection.

However, the S-300 missile was found to be the best option for the system to use as an interceptor. If the S-300 launched right after its 42 seconds of operation delay, it would still intercept the incoming missile over 3 seconds faster than the KS-1 which only had a delay of 30 seconds.

In conclusion, only two out of the four possible missiles that could be used for interception actually had the capacity to intercept the incoming missile, but the S-300 meets the criteria to intercept the incoming missile as quickly as possible without compromising the safety of the surrounding population.

Due to the variety of scenarios and factors that can be added to this problem, future projects can be done based on multiple scenarios and adding factors such as the mass of the missile, air resistance, wind direction, and/or even coming up with a computer algorithm that can be used in such embedded systems. 
NOMENCLATURE

\begin{tabular}{|llc|}
\hline Symbol & Description & Units \\
\hline$\theta$ & Angle & Degrees \\
\hline $\boldsymbol{i}$ & Acceleration & $\mathrm{m} / \mathrm{s}^{2}$ \\
\hline $\boldsymbol{i}$ & Horizontal Component & - \\
\hline $\boldsymbol{j}$ & Vertical Component & - \\
\hline$t$ & Time & $s$ \\
\hline$t_{\text {critical }}$ & Time for missile to be at critical height & $s$ \\
\hline$t_{\text {intercept }}$ & Time of Intercept & $s$ \\
\hline$t_{\text {delay }}$ & Operational delay of the intercepting missile & $s$ \\
\hline $\boldsymbol{v}$ & Velocity & $\mathrm{m} / \mathrm{s}$ \\
\hline$y_{\text {critical }}$ & Critical Height & $\mathrm{m}$ \\
\hline
\end{tabular}

\section{REFERENCES}

Calculus, Early Transcendental Functions.Fourth Edition.Houghton Mifflin, 2007. Print.

Jewett, John W., and Raymond A. Serway. Physics for Scientists and Engineers. 7th ed.

Belmont, CA: Thomson Brooks/Cole, 2008. Print. 


\section{APPENDIX}

\section{MATHEMATiCA CODE}

Calculations for the KS-1 Missile (Velocity: $750 \mathrm{~m} / \mathrm{s}$, Operational Delay: $30 \mathrm{~s}$ )
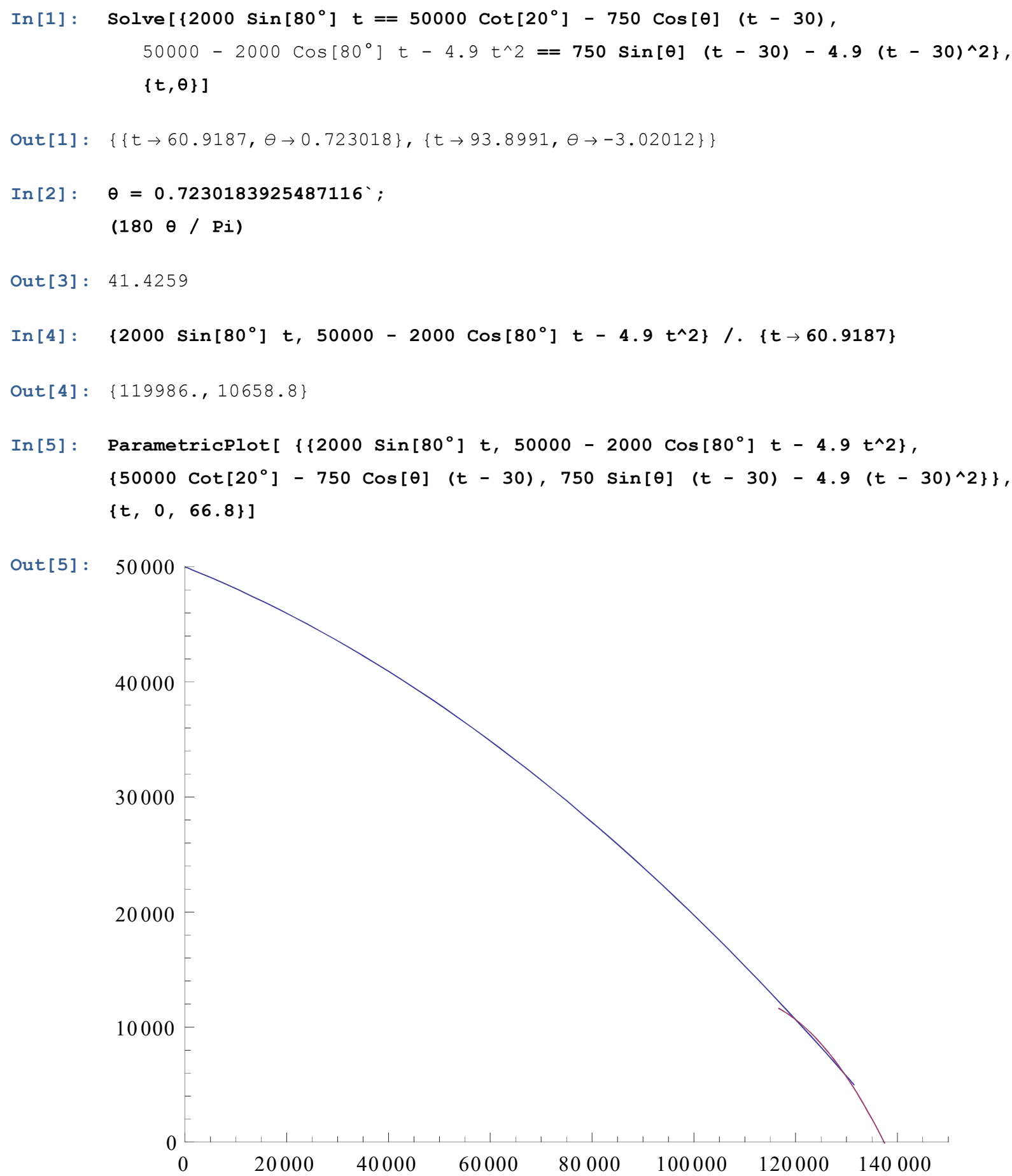
Calculations for the S-300 Missile (Velocity: $1800 \mathrm{~m} / \mathrm{s}$, Operational Delay: $42 \mathrm{~s}$ )

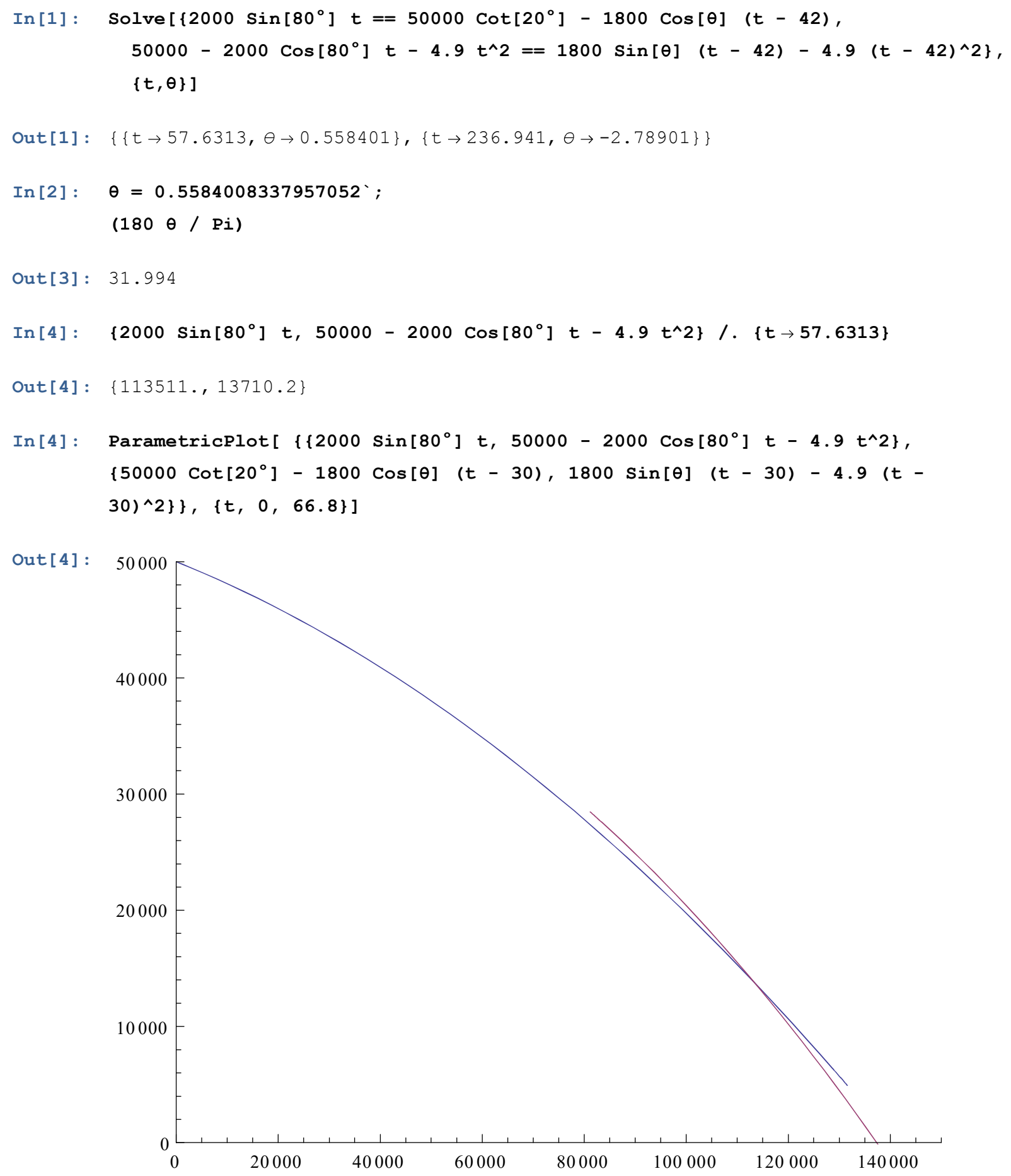

